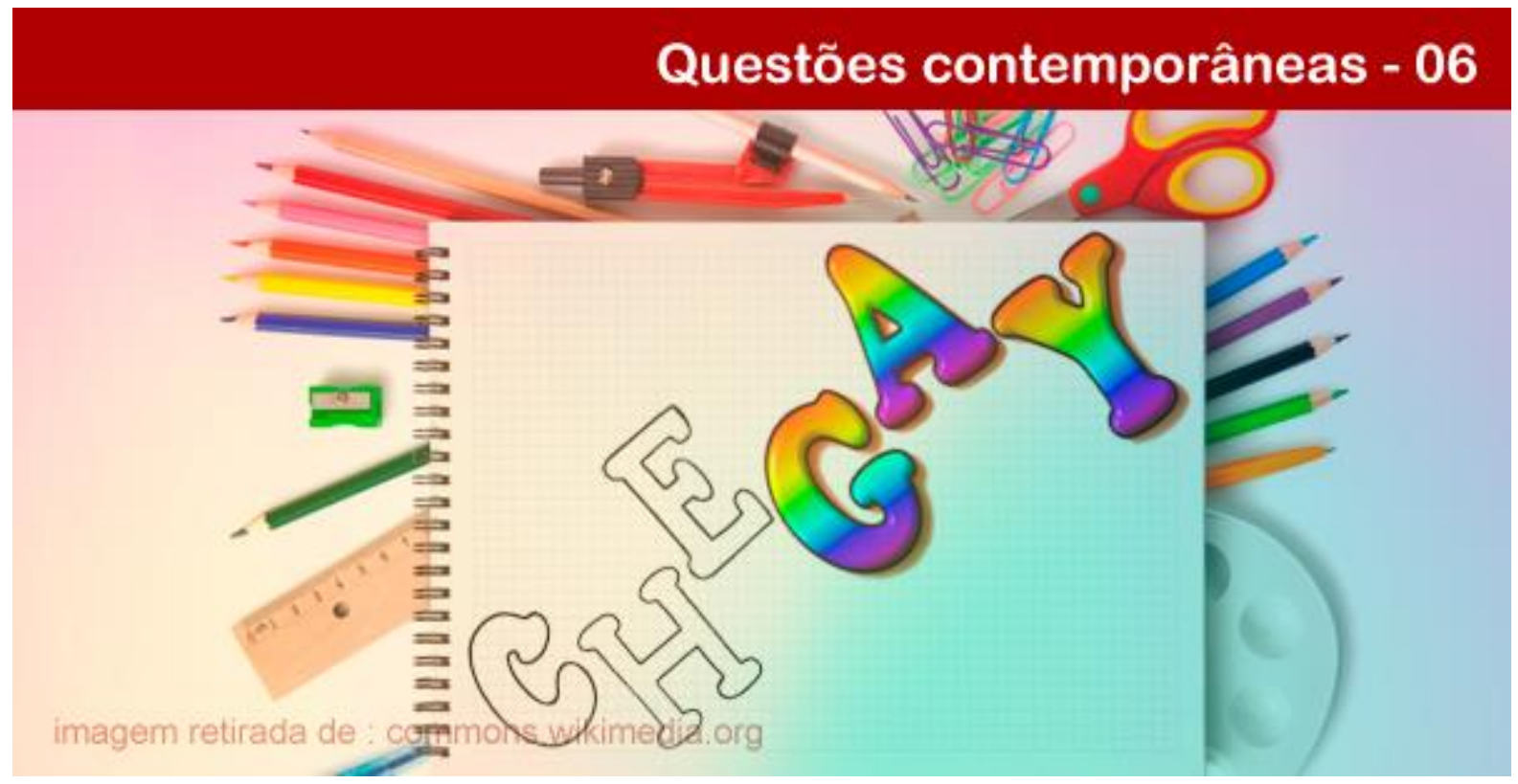

\title{
CHE(GAY), BRILHEI, TOMBEI E LACREI! O QUE FAREMOS COM ESSES MENINOS AFEMINADOS? NOTAS SOBRE TRAVESTIS EM AMBIENTE ESCOLAR
}

\section{Fernando Guimarães Oliveira da Silva}

Doutorando em educação pela Universidade Estadual de Maringá - UEM/PR. Mestre em educação pela UEMS - Paranaíba/MS. Pedagogo pela UFMS - Três Lagoas/MS. Professor das Faculdades Integradas de Três Lagoas - AEMS e Coordenador do CRAS na Prefeitura Municipal de Ilha Solteira/SP. Integra o Núcleo de estudos e pesquisas em diversidade sexual - NUDISEX da UEM/PR. E-mail: fernando.ufms@ hotmail.com.

Resumo: Ainda que os discursos de profissionais da educação insistam em afirmar que não há preconceito sobre estudantes travestis nas escolas, as graves cenas e índices de homo/transfobia nos oferecem dados relevantes de que ainda não é um tema para se esgotar a discussão. Acreditando, inicialmente, que as questões que envolviam orientações individuais dos estudantes não seriam acionadas, as escolas desenvolviam suas práticas com base em padrões sexistas. De maneira ilusória alimentavam a crença de que os meninos e meninas se tornariam a forma hegemônica da heterossexualidade. Entretanto, no pátio das escolas, nota-se a presença de sujeitos em que os marcadores (vestimentas, atitudes, corporalidades) que antes tinham o gênero masculino e feminino como limite, já não conseguem mais identificar. Com base nessa problemática suscitada, este estudo utiliza da pesquisa exploratória para levantar a bibliografia necessária para um percurso que ofereça condições de analisar as dificuldades enfrentadas pelas estudantes travestis nas escolas, devido às hierarquias reproduzidas que induzem a identidades sexuais e de gênero heterossexualizadas. Assim, as escolas estão diante do desafio de tratar as estudantes travestis a partir da construção do gênero que elas fazem em suas corporalidades, ou continuar reproduzindo a lógica heteronormativa que insistem em desconsiderá-las.

Palavras-chave: Escola. Travestis. Heteronormatividade.

\section{ARRIVED, SHONED, TUMBLED AND SEALED! WHAT WILL WE DO WITH THESE EFFEMINATE BOYS? NOTES ON THE TRANVESTITES IN THE SCHOOL ENVIRONMENT}

Abstract: Although the professional discourses of education insist in saying that there is no prejudice about transvestites students in schools, serious scenes of homo/transphobia in offer relevant data that is not a theme to exhaust the discussion. Believing initially that the issues involving individual orientations of the students would not be triggered, schools developed their practices based on gender standards. Illusory way fed the belief that boys and girls would become the hegemonic form of heterosexuality. However, in the courtyard of the schools,

\section{POLÊM!CA | LABORE (3)}

Polêmica - Revista Eletrônica da Uerj - Rua São Francisco Xavier, 524, $1^{\circ}$ andar bloco D, sl.1001 • Tels.: +55 21 2334-4088/4087 • http://www.e-publicacoes.uerj.br/index.php/polemica/index http://www.labore.uerj.br • laboreuerj@yahoo.com.br 
there is the presence of subjects in which the markers (clothing, attitudes, corporalities) that previously had male and female as a limit, can no longer identify. Based on this issue raised, this study uses the exploratory research to raise the bibliography needed for a route that offers the ability to analyze the difficulties faced by students transvestites in schools due to played hierarchies that induce sexual and gender identities heterosexualized. Like this schools are faced with the challenge of dealing with students transvestites from the construction of gender that they do in their corporeality, or continue playing the heteronormative logic insist disregard them.

Keywords: School. Transvestites. Heteronormativity.

\section{Introdução}

Há cerca de 10 anos a Secretaria de Educação Continuada, Alfabetização e Diversidade (SECAD) do Ministério da Educação e Cultura (MEC) formalizava as concepções de gênero, sexualidade e orientação sexual como constructos relacionados com o campo da ética e dos direitos humanos. Ainda nos dias atuais o debate é intenso quando o assunto se propõe a compreender o cotidiano de estudantes lésbicas, gays, bissexuais, travestis e transexuais (LGBTT) nas escolas. Apesar da carência de práticas de formação contínua para preparar os profissionais da educação, os estudos afins demonstram que o tema tem sido ampliado como objeto de pesquisas na área da educação nos últimos anos, cujos enfoques desdobram-se em compreender as construções das sexualidades e a maneira como a escola tem lidado com essa questão.

É evidente, também, a ampliação dos enfoques de pesquisas, principalmente a partir dos reconhecimentos conquistados pelo grupo LGBTT na primeira década do século XXI, o que tem promovido debates de bases empíricas e teóricas em diversas áreas, não ligadas exclusivamente à educação. Todavia, debates e eventos que possibilitam discutir essa problemática permanecem sem ocasionar alterações significativas nas práticas de professores/as, gestores/as e comunidade escolar.

Como se sabe, o documento dos Cadernos SECAD efervesceu, sem dúvida alguma, a necessidade de que os/as profissionais da educação revisassem seus conceitos sobre sexualidades e gênero. Antes mesmo de firmar as possibilidades que o documento trouxe para as práticas pedagógicas e para a rotina escolar, observa-se pendente, ainda, o reconhecimento das expressões particulares de gênero de estudantes travestis, mais especificamente, a subversão que fazem do socialmente instituído para o gênero masculino. Como reflexo disso, dada a acirrada disputa de interesses, no âmbito das escolas ainda prevalecem práticas religiosas e limitadoras do que pode, ou não, ser feito pelos meninos e pelas meninas (LOURO, 1997).

\section{POLÊM!CA $\mid$ LABORE}


Dessa maneira, as noções de gênero e sexualidade cunhadas pelos Cadernos SECAD trazem a desconstrução de ideias essencialistas e naturalizantes, presas em diferenças biológicas entre homens e mulheres, para assumir a defesa de que o gênero é construído socialmente pelos sujeitos nas relações que criam com os seus desejos. O compromisso firmado pelo documento objetiva desestabilizar tradições e, por assim dizer, "derreter sólidos" (BAUMAN, 2001, p. 10) historicamente marcadores de práticas escolares, do viés normalizador, disciplinador, classificatório, normativo e, mesmo, inflexível.

Ao problematizar este assunto, o pressuposto é de que o espaço escolar é lugar de interações sociais mapeadas de ideias, representações, discursos e práticas que incitam, regulam e interditam sentidos conservadores e religiosos sobre a sexualidade. Impera, com isso, um tratamento (se é que é tratado) do tema sob uma lógica heteronormativa, ou o silêncio dos profissionais da escola torna as questões de diversidade sexual inquestionáveis. Aliada a esta perspectiva, desde cedo, muitas estudantes travestis que estão construindo seu gênero enfrentam contextos hostilizantes nas escolas, com insultos, xingamentos, piadas e cenas de exposição. Em certos casos são naturalizadas pelas vítimas - assujeitamento, como veremos em Andrade (2012) - e, em outros, dependendo das proporções tomadas, culminam no abandono e evasão escolares.

Deste modo, objetiva-se entender o que as escolas fazem com os meninos que elas consideram afeminados, considerando-se as relações das travestis com as normas de gênero e a possibilidade de se utilizar desses espaços para construir um contrapoder e uma resistência capazes de afirmar que existem possibilidades, sim. Para tanto, no primeiro momento são analisadas as principais abordagens sobre a questão da escola e sua organização, buscando aproximações com a homo/transfobia naturalizada em práticas hierarquizadas e classificatórias. A partir da análise desse levantamento bibliográfico da pesquisa exploratória será possível compreender a marcação nas travestis de identidades ilegítimas. Essa compreensão reflete o modo como usufruem do acesso, a permanência e as possibilidades criadas para converter esse quadro transfóbico existente nas escolas. A proposta é oferecer condições para uma cheg(ay)ada, brilho, tombada e lacrada, como bem assinala o universo discursivo delas.

Foucault (2004) afirmava que onde há uma complexidade de relações de poderes, também há contrapoderes, resistências. O uso do universo discursivo das travestis por meio

\section{POLÊM!CA $\mid$ LABORE}


dos dizeres "Che(gay), brilhei, tombei e lacrei" vem para convidar o espaço educacional a repensar as possibilidades de lidar com modos de ser, mais inventivos, e sobretudo uma prática que se apresenta como um contrapoder, uma resistência. A proposta desses dizeres propõe um efeito de sentido que coaduna com possibilidades de vazão de outras formas de ser e estar nos espaços educacionais. A produção do contrapoder e da resistência oferece condições para as estudantes travestis não serem vistas como estranhas e anormais pelas pessoas da comunidade escolar.

Além disso, os dizeres "Che(gay), brilhei, tombei e lacrei" visam problematizar corporalidades travestis no ambiente escolar. Significa dizer, com isso, que só é possível desconstruir a fobia sobre elas nas escolas, se oferecidas as condições de brilho, por meio de ações que contribuam para a transposição dos muros que se criam. A escola pode oferecer condições de problematizar a construção corporal dessas travestis a partir da transversalidade proposta pelos PCNs nas diversas disciplinas curriculares, pensando numa proposta de estudos de identidade de gênero.

Já no que se refere a tombar, assegura-se o reconhecimento das travestilidades em ambiente escolar, visando, assim, evidenciar as barreiras e oficializar a necessidade de que as identidades trans só podem ser tombadas se houver reconhecimento e respeito aos direitos humanos e sexuais delas, quer em sociedade, quer nas escolas.

Depois de tombado esse reconhecimento, fecha-se uma proposta de vazão de possibilidades de se viver a potência da diferença com um "lacre". As estudantes travestis só podem selar os itinerários preconceituosos para lacrar experimentando a plenitude do reconhecimento de suas identidades de modo saudável e tranquilo, sem sinuosidades que fragilizam seu envolvimento com a comunidade escolar. Os sentidos atribuídos ao enunciado "lacrou" designam o êxito obtido em algum evento, mesmo que passageiro. Diante disso, o lacre desse estudo representa o êxito vivido pelas estudantes travestis ao experimentarem itinerários escolares livres de fobia.

\section{Apontamentos de uma escola que segrega sexualidades}

O assunto diversidade sexual nas escolas no Brasil suscita explicações cujas definições provêm de contextos historicamente responsáveis por assegurar que a escola não seja um espaço em que se discuta sexualidade, principalmente porque os defensores da ideia de que gênero e sexualidade ocupam a esfera da intimidade na vida das pessoas colocam estas

\section{POLÊM!CA $\mid$ LABORE}


questões como secundárias nas práticas das escolas (GRAUPE; GROSSI, 2013). Como essa temática é entendida como algo não deslocado da prática pedagógica de professores/as; diversos movimentos em planos, conferências e secretarias de educação promovem o silenciamento de debates dessa natureza na escola.

A seara do tema atravessa, ainda, discussões polêmicas sobre a proposta da Escola Sem Partido. O Professor Fernando de Araujo Penna, da Universidade Federal Fluminense (UFF), aponta que essa discussão existe desde 2004 e sua força ganha visibilidade num contexto de potentes ofensas conservadoras nos espaços que deveriam ser públicos e assegurar a vivacidade de novos modos de ser. No ano de 2015, em entrevista concedida à Revista Movimento, Penna (2015) afirmava que as discussões da Escola Sem Partido despontaram-se a partir do combate à doutrinação de esquerda. Complementa o professor: “é justamente no momento que o Escola Sem Partido se aproveita do combate à ideologia de gênero, tornando-o uma das suas bandeiras, que ele dá um salto qualitativo" (PENNA, 2015, p. 297).

Fortalecendo-se na falsa crença de que já não estaria assumindo um Partido, o Programa Escola Sem Partido discute a prática docente. Limita o trabalho docente sobre temáticas políticas, socioculturais e econômicas, acreditando, com isso, que o/a professor/a deve respeitar a educação moral dos pais e das mães oferecidas aos/às seus/suas filhos/filhas. Observa-se que essa discussão acaba por tolher o trabalho do/da professor/a com questões relativas a um projeto de redução das desigualdades e diversidade de gênero.

Esse modo de guiar a prática docente e escolar revela-se dissonante do que é disposto em documentos e dispositivos legais anteriores, como é o caso dos Parâmetros Curriculares Nacionais (PCN), diretrizes e, também, a Lei Maria da Penha (Lei n ${ }^{\circ}$ 11.340/2006), que garante que as práticas escolares iniciem um trabalho educativo vinculado à desconstrução de desigualdades entre os gêneros. Esses dispositivos apontam para possibilidades de trabalhar gênero e sexualidade como forma de superar desigualdades entre homens e mulheres que “inventam" (FOUCAULT, 1985, p. 137) no corpo um dado biológico. Nesse modelo naturalizante, pressupõe-se que os corpos das pessoas são conectados com as práticas sexuais e com a maneira como se identificam com o mundo. As práticas educativas, então, em nada estariam erradas se reforçassem o trabalho com a binaridade de cores, sentimentos, posturas e atitudes, entre outros comportamentos ligados, diretamente, à anatomia.

\section{POLÊM!CA $\mid$ LABORE}


Para contribuir com o reforço das diferenças, Louro (1997) atesta que a escola veio demarcando, tradicionalmente, altura e postura, modos de se relacionar, regras e valores religiosos acreditados, por muitos, como indispensáveis para a manutenção da harmonia entre os estudantes e profissionais da educação. Por meio desse arsenal de práticas segregadoras, a autora afirma que a escola contribuiu muito para a construção escolar das diferenças em atividades polarizadoras por meio do currículo, normas, linguagens, materiais didáticos, formas de tratamento e outros, que consolidam e fabricam as diferenças.

Esse modelo de práticas escolares segregadoras pode ser descrito, também, como uma forma de controlar e vigiar os corpos, para que não fujam dos limites predispostos para os sexos. Segundo Foucault (1987, p. 230), pensar a educação significa entender as escolas e sua instrumentalidade no processo de produção das subjetividades que se realiza por meio de

[...] penalidade, a vigilância e o controle seriam então uma maneira de gerir as ilegalidades, de riscar limites de tolerância, de dar terreno a alguns, de fazer pressão sobre outros, de excluir uma parte, de tornar útil outra, de neutralizar estes, de tirar proveito daqueles.

Essas atividades de disciplinamento dos corpos das pessoas não são feitas por meio de sistemas essencialmente repressivos, mas por meio de práticas sutis que passam despercebidas pelos sujeitos e modelam suas representações. Com isso, percebe-se que a escola tem o poder de normalizar, ora cria padrões, ora um sistema de regras que determina sanções àqueles que as transgridem. Geralmente, estas regras são acreditadas como princípios fundamentados em valores e moralidades (LOURO, 1997).

Parece consenso que a escola precisa adquirir uma postura baseada nos limites biológicos para oferecer um tratamento condizente com as necessidades educativas de seus/suas estudantes. As principais críticas que descaracterizam esse modelo estão relacionadas à desconstrução do gênero aliado ao sexo (macho e fêmea); à valorização, pelas práticas escolares, das identidades de gênero de seus estudantes; e à possibilidade de que estudantes transgêneros (travestis e transexuais) sejam tratadas pelo seu nome social e façam uso de banheiros correspondentes à sua identidade de gênero. Outro equívoco desse modelo biologicista consiste na crença de que estudantes travestis convivem apenas com conflitos identitários de escolhas de caráter individual e que, sobretudo, representam uma fase.

Nas escolas brasileiras, esse modelo biologicista não foi superado, uma vez que muitas insistem em assegurar que meninas sejam mulheres e meninos sejam homens. Além do que,

\section{POLÊM!CA $\mid$ LABORE}


como assinala Louro (1997), a escola tem sido uma extensão das práticas familiares, por sua vez, as crianças são cobradas pelos pais a manterem essa lógica heterossexista.

Em Foucault (2004), por exemplo, as relações sociais no espaço escolar são compostas de representações que regulam os sistemas de comunicação entre os sujeitos, baseadas em disciplinas e técnicas de vigilância, às quais se sobrepõem sentidos heterossexistas. Trata-se de compreender que a escola exerce um papel fundamental na subjetivação normativa ${ }^{1}$ dos estudantes, colocando em exercício práticas reguladoras de sentimentos, posições assimétricas, que classificam rigidamente os limites entre os gêneros.

Esse modelo normativo é criado, segundo Foucault (2004), para articular poder e saber na produção de uma pessoa. Para o autor, o discurso tem o poder de vincular uma pessoa ao contato com regimes de verdades instituídos em sociedade. Dessa maneira, todo discurso tem o papel de instrumentalizar o contato com uma verdade e a escola "têm por objetivo vincular os indivíduos ao processo de produção; trata-se de garantir a produção em função de uma norma determinada" (FOUCAULT, 2003, p. 114).

A partir desse modelo de produção dos sujeitos, observa-se que as escolas ainda insistem em produzir e gerir pessoas com essa formação sexista, homofóbica e assimétrica. Como uma estratégia na formação de subjetividades normativas, a escola também pode representar espaço de resistência, assim é o caso dos estudos que contemplam os profissionais da educação sobre o modo como estas subjetividades normativas trazem dificuldades no processo de constituição e representação identitária de estudantes travestis.

Um discurso que desconstrói a perspectiva de caráter biológico está presente nos estudos de Butler (2010), que promove novas leituras a respeito das questões do sexo, gênero e sexualidade, desalinhando essa sequência. A autora considera que inscrever marcas no corpo é uma ação desnecessária, porque o corpo das pessoas não é um instrumento passivo e/ou receptáculo de cultura; o corpo é o local em que se materializa uma linha de subjetivação.

Baseando-se na crítica ao modelo biologizante, que ancora muitos discursos sobre a subjetivação normativa, os estudos de diversidades sexuais reivindicam a possibilidade de desalinhar sexo, gênero e sexualidade (LOURO, 2009). Consequentemente, as questões que

\footnotetext{
${ }^{1}$ Entende-se subjetivação normativa processos que "dizem respeito à produção de sujeitos que reproduzem os modelos previamente dados, e dão manutenção a certo modo de viver disciplinado, regulado e repetitivo. São os filhos e as filhas da "norma" (PERES, 2010, p. 58).
}

\section{POLÊM!CA $\mid$ LABORE}


dicotomizam a formação dos estudantes apenas pelo viés do que é de menino e de menina, já não corroboram mais com uma política de formação para compreender a diversidade, uma vez que as escolas têm um grupo significativo de estudantes em que os marcadores sociais de gênero se entrecruzam a todo o momento.

Observando-se estes novos modos de ser que comparecem à cena escolar, revela-se oportuno desconstruir práticas sexistas e assumir uma postura condizente com o exercício do respeito do modo como constroem seus corpos, gênero e sexualidade. Por essa via, as escolas precisam (re) configurar suas práticas para tornar o ambiente escolar menos agressivo, combatendo possíveis situações de transfobia. Dessas possibilidades de acolhimento escolar de estudantes travestis, desenvolvem-se novas questões para o trato com os discursos marcadores de normalidades e normatividades sobre comportamentos, atitudes e práticas sociais - modos de agir, sentir e pensar. Assim, estudantes trans, bi, homo e heterossexuais não se apresentam mais como dicotômicos e materializados em características biologizantes, mas em práticas sociais, completamente articuladas e concomitantes.

Contudo, em razão da necessidade de desconstruir essas regras naturalizantes, tornamse urgentes processos de formação contínua e também inicial de docentes capacitados/as para lidarem com as questões da diversidade sexual. Em nome dessa urgência, o cotidiano hostilizante de estudantes travestis reflete o abandono escolar por conta do ambiente agressivo que este espaço traz para suas convivências (PERES, 2009).

Como consequência disso, Seffner (2009, p. 132) propõe que para a escola se tornar um ambiente de inclusão de estudantes gays, lésbicas e trans é preciso que haja uma mudança na estrutura escolar. Enfatiza, com isso, que se deve começar pela

\footnotetext{
Abolição das piadas e das manifestações sexistas, tão comuns entre professores e professoras, acerca dos alunos e das alunas "diferentes" dos padrões heterossexuais ditos "normais". Não é possível educar num ambiente de falta de respeito, e a agressão - verbal e até mesmo física - tem sido uma arma de expulsão de indivíduos que não se enquadram na regra da heteronormatividade
}

Complementa o autor que não é por conta da necessidade de problematização da questão da sexualidade de estudantes que a escola será um espaço em que o desrespeito vai ser liberado, mas se estudantes heterossexuais podem demonstrar explicitamente que se relacionam, é válido também que estudantes homo e transexuais o possam, em padrão de equidade. Entretanto, acredita-se que exigir que a escola, enquanto espaço público, respeite

\section{POLÊM!CA $\mid$ LABORE}


que estudantes LGBTT demonstrem seus relacionamentos seria, ironicamente, avançar demais, uma vez que a discussão desse estudo abrange, ainda, a possibilidade de desconstruir os sólidos discursos biologizantes na cultura e prática escolares.

Do mesmo modo, Peres (2009, p. 245) pondera, em seus estudos, a dificuldade da escola em tratar sobre orientação sexual e identidade de gênero, pois estas questões não estão presentes em seus manuais; com isso ela "reifica os modelos sociais de exclusão por meio de ações de violência (discriminação e expulsão) ou de descaso, fazendo de conta que nada está acontecendo (não escuta as denúncias da dor da discriminação).” É importante lembrar também que as possibilidades de tratar, em padrão de equidade, questões heterossexistas e de diversidades sexuais, não significa ignorar completamente o discurso biologizante, mas importa a partir dele promover contatos com outras formas de se construir, no que se refere à sexualidade e ao gênero (JUNQUEIRA, 2009).

É inquestionável, portanto, a necessidade da revisão das práticas escolares heterossexistas na educação brasileira para tornar as escolas um ambiente de pleno desenvolvimento para estudantes LGBTT. Essa afirmação se faz pertinente quando percebe-se que as vidas de travestis são ceifadas pela fobia que se iniciam, em muitos casos, em discursos notadamente carregados de piadas grotescas que naturalizam o processo de destituição de normalidade no corpo delas. Além dessa problemática, Peres (2009, p. 256) complementa que

\begin{abstract}
Diante disso, o contato com a realidade das travestis aponta e afirma que tanto os gêneros quanto os corpos e as sexualidades só podem ser entendidos como construções sociais e históricas marcadas pela cultura, com seus sentidos e significações pertinentes, com seus processos de subjetivação.
\end{abstract}

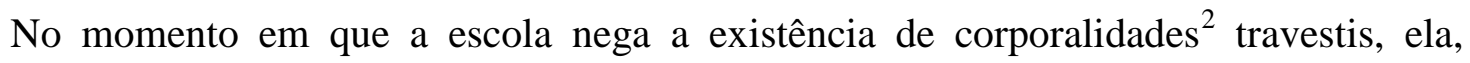
simbolicamente, comunica "as oposições binárias (fixas e polarizadas) entre o masculino e o feminino, a heterossexualidade e a homossexualidade, o certo e o errado, o normal e o patológico, o pecado e a virtude" (PERES, 2009, p. 257). Sempre dicotômica, o discurso de

\footnotetext{
${ }^{2} \mathrm{O}$ conceito de corporalidades usado tem base em Deleuze ao considerar que somos constituídos por multiplicidade, o que enquanto sujeitos somos responsáveis por expressar diversas formas de ser e estar nos lugares sociais. Com isso, o autor diz que somos constituídos de "Uma multiplicidade não numérica, pela qual se define a duração ou a subjetividade, mergulha em outra dimensão puramente temporal e não mais espacial: ela vai do virtual a sua atualização; ela se atualiza, criando linhas de diferenciação que correspondem a suas diferenças de natureza. Uma tal multiplicidade goza, essencialmente, de três propriedades: da continuidade, da heterogeneidade e da simplicidade" (DELEUZE, 1999, p. 32).
}

\title{
POLÊM!CA $\mid$ LABORE
}


formação biologizante das relações entre os gêneros supõe identidades cristalizadas, rígidas e inquestionáveis. À medida que contribui para a reprodução dessa lógica heterossexista de subjetivação, a escola inicia um regime de (in) visibilidade por meio de práticas que desconsideram a presença de estudantes travestis em seu espaço. Esse, aliás, parece ser o entendimento dos profissionais das escolas quando se dirigem a estudantes travestis pelo nome de origem ou impedem o uso do banheiro feminino. Apesar de estarem admitindo essa lógica que supõe que todos/as sejam heterossexuais, ainda exercem, por meio dessa prática, exigências mínimas para qualificação do acesso e permanência nas atividades escolares.

Outro assunto relevante para a análise da imposição desse discurso biologizante são os elementos constitutivos da representação sobre o ser travesti que permeia a formação identitária que as pessoas criam sobre elas. De início, os discursos geralmente as associam às identidades promíscuas e que escandalizam comportamentos femininos em suas corporalidades, como se elas fossem incapazes de entender os limites entre o respeito e o desrespeito em lugares sociais. Essa representação identitária permeia os imaginários sociais dos profissionais da escola. No entanto, na pesquisa de doutoramento de Luma Nogueira de Andrade (2012), travestis jovens de três escolas públicas estaduais do Ceará trouxeram novas formas de travestilidades, distintas daquela mobilizada pela sociedade de que travestis é sinônimo de prostituição.

Andrade (2012) deslocou da margem os estudos sobre travestilidades para entendê-las, conforme pontua a autora, no centro da sociedade. Isso não significa que a autora desconsidera as pesquisas que abrangeram travestilidades no lócus das esquinas e de prostituição, mas que investiga resistências e o assujeitamento à normatividade imposta pelas escolas. Em sua tese, conclui que

\footnotetext{
As resistências ou assujeitamentos podem ser opostos e complementares simultaneamente, pois mesmo ao se assujeitar as travestis estão fazendo uso de tática para permanecer na escola, promovendo uma crise na forma tradicional como é conduzida esta em relação aos gêneros, induzindo mesmo que paulatinamente mudanças e aberturas no presente e no futuro. A presença das travestis nas escolas se apresenta como dispositivo relevante para a formação da comunidade escolar na convivência com as singularidades delas, mesmo em meio a profundos conflitos (ANDRADE, 2012, p. 248)
}

Uma postura de heteronormatividade permeia a relação das estudantes travestis com os profissionais da educação. Andrade (2012) afirma que, ao mesmo tempo em que as travestis se assujeitam à cultura heteronormativa das escolas, também resistem a ela, uma vez

\section{POLÊM!CA $\mid$ LABORE}

Polêmica - Revista Eletrônica da Uerj - Rua São Francisco Xavier, 524, $1^{\circ}$ andar

bloco D, sl.1001 • Tels.: +55 21 2334-4088/4087 • http://www.e-publicacoes.uerj.br/index.php/polemica/index

http://www.labore.uerj.br • laboreuerj@yahoo.com.br 
que isso simboliza uma estratégia para permanecer e alcançar, por meio da educação, a possibilidade de desconstruir destinos predefinidos às ruas e à prostituição.

Acerca desta questão, o que também nos leva a problematizar esse assunto é a pesquisa de mestrado de Keith Braga (2014) que, ao investigar boletins de ocorrência escolares, trouxe que profissionais da educação, especialmente professores/as mediadores/as de conflitos escolares, orientaram os estudantes homossexuais a agirem menos afeminadamente e a serem mais discretos. Essa postura emerge de um sistema cultural heterossexista de correção e culpabilização do estudante homossexual pela violência sofrida, justificando o conflito pelo desrespeito que o estudante teve com os limites fronteiriços entre os gêneros (LOURO, 2008). Ainda que esta análise não seja voltada para as travestilidades, oportuniza uma leitura de como estudantes LGBTT são cobrados a serem mais discretos, o que pode remeter a uma violência ainda maior quando se considera que estudantes trans ultrapassam estes limites.

\section{Che(gay), brilhei, tombei e lacrei! $O$ que faremos com estes estudantes afeminados?}

Como apontado nas pesquisas de Andrade (2012) e Braga (2014), estudantes travestis e homossexuais convivem em escolas que legitimam práticas de expulsão, constrangimento e correção dos corpos LGBTT por meio de um discurso de aversão que dicotomiza e polariza os gêneros. Ao iniciar a discussão desse item, com o texto "che(gay), brilhei, tombei e lacrei", a condução reflexiva pretendida visa promover deslocamentos nos/as profissionais das escolas para que as práticas mobilizem novas formas de lidar com corporalidades trans.

Em relação às corporalidades trans, ressalta-se que a produção da subjetivação das travestis desconstrói padrões socialmente instituídos e demarcados como alinhados ao masculino e ao feminino. No entanto, as diversas formas de se apresentar numa corporalidade trans nos oferecem novas maneiras de lidar com a questão. Assim, meninos em muitos casos iniciarão um processo de uso de roupas e a transformarem seus corpos, de acordo com perfis femininos. Geralmente, atitudes, fala e comportamentos vão se transformando e, com isso, seus corpos e formas de comunicação vão construindo um "gênero ambíguo, borrado, sem limites e separações rígidas" (BENEDETTI, 2005, p. 131).

Conectada com essas discussões, em debate recente sobre a identidade trans trazida pela Revisa Nova Escola, em fevereiro de 2015, com o título "Vamos falar sobre ele? Como

\section{POLÊM!CA $\mid$ LABORE}


lidar com um aluno que se veste assim: uma reflexão sobre sexualidade e gênero", aparece a emergência da discussão sobre identidades trans em ambiente escolar e o trato com a questão, objetivando diminuir práticas de transfobia e assegurar direitos de cidadania, como nomes sociais e a construção física da identidade de gênero nas escolas.

Um dos consensos resultantes da análise feita por Wellinton Soares (2015), na revista, foi o de que a escola cumpre com o papel de reconhecer o direito à educação de estudantes trans, mas as silencia, porque são frutos de acordos entre políticos e milionárias instituições religiosas que impedem que esta discussão seja possível, ao passo que acreditam que emergiriam possibilidades de garantir a livre construção do gênero.

Essa noção de identidade de gênero inviabiliza que a escola seja um espaço em que o normativo das relações heterossexistas acontecem. Mesmo porque, como o próprio autor bem assinala, a escola não quer tocar em assuntos sagrados para instituições religiosas e o Estado, porque pode limitar o processo de dominação que produzem.

Corroborando com esse ponto de vista, Elizabete Cruz (2011) ressalta que as travestis convivem com muitas dificuldades nas escolas, não necessariamente advindas de outros/as estudantes, mas de professores/as e gestores/as. Em sua pesquisa, muitos/as professores/as e gestores/as preocupavam-se em buscar alternativas para lidar com a diferença de estudantes travestis, no entanto, “esta busca quase sempre era pautada por uma perspectiva binária (ou isto ou aquilo, ou homem ou mulher) em premissas religiosas, ou científicas - classificatórias e patologizantes" (CRUZ, 2011, p. 75). Objetivamente, isso implica que as escolas não associam as dificuldades vividas pelas estudantes travestis às atividades educativas como uma forma de propor um conhecimento que revise a maneira como as pessoas consolidam seus discursos de anormalidade.

Cria-se uma compreensão de que não há o que se questionar sobre o assunto, uma vez que se alimenta um suposto consenso de desrespeito às identidades das estudantes. O objetivo deste estudo é desvencilhar-se de práticas heterossexistas que descaracterizam presenças de pessoas LGBTT nas escolas. Esse sistema classificatório que permeia as práticas da escola, conforme Elizabete Cruz (2011) pondera, torna-se reforçado no momento em que professores/as e gestores/as são indagados/as sobre o uso do banheiro, o que levaram às respostas de que

\section{POLÊM!CA $\mid$ LABORE}


Nosso binário modo de funcionar dividiu os meninos - pênis para um banheiro e as meninas - vaginas para outro. Quando no cotidiano da escola (e das sociedades) surgem aqueles que fogem ao processo classificatório estabelecido a confusão se estabelece. Não há banheiro para uma Joana com pênis. Porque a Joana com pênis não é familiar é "estranho". E o que fazemos então? (CRUZ, 2011, p. 78).

Para que estudantes travestis não sejam maltratadas ou discriminadas, muitos/as profissionais indicam a possibilidade de uso do banheiro de professores/as. A mesma pesquisadora afirma a incongruência de gestores/as assumirem esta possibilidade, porque reitera uma postura de que o banheiro dos/as professores é assexuado. Por desempenharem, nestas instituições escolares, o papel de (re) produtores/as das diferenças, eles/as não criam condições de problematizar os silêncios em torno do não dito, do estranho e do anormal.

A propósito disso, Bortolini (2008, p. 674) trouxe distanciamentos de discursos de professores entre ter um/a filho/a homossexual ou uma filha travesti, acrescentando que surgem mais dificuldades de aceitação no que se refere às travestilidades e à transexualidade. As pesquisas sobre travestilidades nas escolas só fazem sentido, segundo o autor, se as estudantes travestis são reconhecidas como identidades, caso contrário, se sua identidade feminina não é reconhecida, consequentemente, não sentido é eficaz discutir o uso do nome social e do banheiro feminino. O pesquisador lembra, ainda, que os reconhecimentos contestados pelas travestis nas escolas, "no fundo, depende de o educador reconhecer ou rejeitar a identidade feminina da travesti. Se ele reconhece, tudo é resolvível. Se, pelo contrário, ele rejeita, tudo é empecilho" (BORTOLINI, 2008, p. 678).

A novidade sobre a desconstrução da regra que regula o sistema de relações entre os gêneros parte da leitura de que "o sexo biológico tomado como dado natural, não problematizado, é o produto de um sistema de representação do mundo, de um regime de verdade que constrói a diferença ao anunciá-la" (SWAIN, 2000, p. 63). Dessa maneira, a representação de que gênero e sexo estão alinhados seria uma ilusão que permeia práticas sociais contidas em discursos de diversas instituições sociais (família, escola, poder judicário e etc). Além disso, em identidades trans, o desrespeito às regras e normas de gênero que o corpo delas fazem, segundo Bento (2011, p. 255), justifica a multiplicidade de situações marginais que as violentam, sendo a mais massacrante a “[...] patologização social [...] pois irradia a convicção de que são pessoas inferiores".

Analisar agora o que deveria ser feito para acolher, ressignificar e transpor o preconceito contra estudantes travestis deveria compor, de maneira tranquila, nossas

\section{POLÊM!CA $\mid$ LABORE}

Polêmica - Revista Eletrônica da Uerj - Rua São Francisco Xavier, 524, $1^{\circ}$ andar

bloco D, sl.1001 • Tels.: +55 21 2334-4088/4087 • http://www.e-publicacoes.uerj.br/index.php/polemica/index

http://www.labore.uerj.br • laboreuerj@yahoo.com.br 
discussões, uma vez apontado que o problema estaria no ajustamento heterossexista que as escolas fazem com seus corpos. Entretanto, há que se pontuar que nenhuma discussão de qualquer assunto se esgota assim. Por isso, é válido considerar as perspectivas de que é possível incluir as travestilidades em dinâmicas escolares menos agressivas e potencializadoras da transfobia. Torna-se pertinente, então, por meio da negociação que é feita entre as identidades normatizadas (heterossexistas) e aquelas que subvertem (travestis), como é discutido por Britzman (1996, p. 74), que "nenhuma identidade sexual - mesmo a mais normativa - é automática, autêntica, facilmente assumida; nenhuma identidade sexual existe sem negociação ou construção".

Em pesquisas já citadas anteriormente, a negociação das identidades travestis em ambiente escolar é mapeada de conflitos. Nos estudos de Peres (2010), por exemplo, analisar as experiências de travestis nas escolas trazem relevantes contribuições para entender como se edificam preconceitos. Em suas pesquisas, o universo de travestis indicou que suas maiores dificuldades se relacionam ao tratamento qualificado à identidade de gênero feminina. A presença delas nos diversos espaços problematizam a leitura biologicista do corpo "afrouxando as amarras do sistema sexo/gênero, para compor novos processos de subjetivação e novas possibilidades de existencialização" (PERES, 2010, p. 61).

Peres (2010) pondera, ainda, ao subverter a identidade normativa, que as estudantes travestis terão um itinerário permeado de convívio desmotivador e desestimulador nas escolas. A demarcação simbólica de uma identidade subversiva refletirá nas condições de tratamento delas. Pensando em condições de permanência, estas estudantes sofrerão com práticas de exclusão e fobias. Com isso,

\footnotetext{
Os relatos evidenciam um mundo de terror e de violência nas quais as pessoas que, na busca de sua felicidade, escolhem romper com os padrões morais estéticos são submetidas às atrocidades dos preconceitos de pessoas viciadas em identidades que acreditam ser os donos da verdade e dos modelos preestabelecidos como a priori dos modos existenciais (PERES, 2010, p. 63).
}

A afirmação de que os itinerários formativos de estudantes travestis nas escolas são negociados em conflitos que representam, em sua maioria, perdas e dificuldades, oportuniza garantir que essa discussão deve ser problematizada pelas escolas e secretarias de educação. Uma proposta para assegurar que a cheg(ay)ada de estudantes travestis nas escolas seja mapeada de brilho (tolerância sobre modos mais inventivos de ser) e lacre (êxito nas

\section{POLÊM!CA $\mid$ LABORE}


possibilidades de se viver de modo diferente), como bem propõe este estudo, é difundida por grupos de estudos e pesquisas sobre diversidades sexuais. Estes grupos, geralmente, elaboram projetos de extensão e pesquisas que envolvem estudantes, professores/as e gestores/as, porém, como o tema é polêmico, pode-se dizer que as ações que envolvem as escolas, em alguns casos tornam-se limitadas.

Vale ressaltar, então, os movimentos realizados pelo Núcleo de identidades de gênero e subjetividades (NIGS), vinculados à Universidade Federal de Santa Catarina (UFSC), possui pesquisadores da graduação, pós-graduação, comunidade escolar e aberta à população local, onde aquela universidade se instala. Entre os anos de 2007 e 2012, o NIGS construiu uma agenda de oficinas que tinha por objetivo combater a homo, lesbo e transfobia nas escolas de Florianópolis.

De acordo com Graupi e Grossi (2013), antes de iniciar as oficinas com as escolas, os integrantes do NIGS passam por uma formação que discute concepções teóricas e metodológicas sobre gênero, sexualidade e violências relacionadas. O objetivo dessa formação é preparar o grupo para lidar com diversas concepções sobre os temas cunhados e promover uma discussão mais voltada às necessidades dos participantes das escolas, principalmente, no que se refere às identidades de gênero e sexual.

A ação desenvolvida pelo NIGS mostrou-se relevante, porque afirmou a premissa de que muitos/as profissionais das escolas acreditam que assuntos sobre sexualidade e gênero são temas que devem ser tratados pelo ambiente familiar (GRAUPE; GROSSI, 2013). Além das ações de formação com professores/as e estudantes, o NIGS também desenvolveu a possibilidade de atuar junto a atividades lúdicas de revisão de conceitos sobre os temas principais de sua proposta. É o caso do concurso de cartazes alusivos ao combate a homo, lesbo e transfobia, que por sua vez buscaram

[...] sensibilizar e desafiar as pessoas a refletirem sobre as questões que dizem respeito à inclusão da discussão sobre a diversidade sexual na escola, à valorização da diferença, à construção de um ambiente de respeito e acolhida para com as diferentes formas de viver a sexualidade e a identidade de gênero (GRAUPE; GROSSI, 2013, p. 229-230)

Há que se realçar, com essa abertura dada pela escola, que o NIGS ofereceu a oportunidade de problematizar as questões que envolvem gênero e sexualidade. Vista pelo olhar do combate aos conflitos entre estudantes LGBTT e heterossexuais, bem como às

\section{POLÊM!CA $\mid$ LABORE}


dificuldades de reconhecimento que estudantes travestis vivem nas escolas, a ação do NIGS oportunizou entender como se enredam e complexificam identidades sociais não normativas no contexto em que a heterossexualidade possui predominância, em muitos casos.

Nesta perspectiva, para responder o que seria interessante que as escolas fizessem com estes estudantes classificados como afeminados, destacam-se as possibilidades que o NIGS trouxe por meio do concurso de cartazes e das oficinas com professores e comunidade local. De acordo com Graupe e Grossi (2013), o concurso promove a criação de cartazes artísticos alusivos ao combate à homo, lesbo e transfobia nas escolas públicas do município de Florianópolis/SC. Ponderam ainda que as ações não estavam voltadas apenas para a competição, mas também, para formar os professores em oficinas sobre o tema.

\begin{abstract}
Durante o período de exposição, os cartazes foram submetidos a três diferentes formas de avaliação e premiação: a) Categoria Prêmio Popular: a comunidade universitária escolheu os três melhores cartazes; b) Categoria Prêmio Científico: foram convidadas via e-mail para fazerem parte da votação online no prêmio científico professores/as que trabalham com estas temáticas referentes ao concurso, representantes de Movimentos LGBT e de Movimentos sociais e estudantis. Vinte e duas pessoas escolheram os três melhores cartazes do Ensino Fundamental e os três melhores do Ensino Médio; c) Categoria Júri NIGS: votaram os pesquisadores (atual ou ex-pesquisadores) do Núcleo de Identidades de Gênero e Subjetividades/NIGS.
\end{abstract}

Uma vez entendido o papel da escola na construção das diferenças, vale considerar que as ações do NIGS propõem práticas significativas para oferecer novas possibilidades de converter os quadros agressivos e potenciais de riscos que vivem estudantes travestis nas escolas, apontando possibilidades para desconstrução de fobias.

Por mais que pareça utópico, acredita-se necessário que esta discussão não pode se esgotar, afinal "a historicidade das relações sociais/sexuais mostra que o importante é aquilo que damos importância. Mudar um regime de verdade não significa apenas mudar de lugar, mas inverter os paradigmas para melhor dissolvê-los" (SWAIN, 2000, p. 81). Considerando que as estudantes travestis desconstroem identidades normativas, torna-se relevante entender que as diversas representações de identidades sociais acontecem e cobram deslocamentos de ideias conservadoras e tradicionais sobre gênero e sexualidade.

\title{
Considerações finais
}

Este estudo exploratório aponta para a evidência da tendência polarizadora da escola em reproduzir práticas classificatórias de identidades normativas. Por meio de dois trabalhos

\section{POLÊM!CA $\mid$ LABORÉ}


aqui citados, Andrade (2012) e Braga (2014), essa evidência vincula-se às ações das escolas, principalmente, porque as estudantes trans vivenciam fobias e a negação de suas corporalidades no contato com o viés normatizador que atravessa representações e práticas tradicionais e conservadoras das escolas.

Recentemente, o contexto político brasileiro tem despontado propostas de diminuição de políticas públicas voltadas para pessoas LGBTT, disseminando-se em práticas que intensificam as formas de silêncio da prática docente. O Programa Escola Sem Partido tem ampliado seus/suas adeptos/as para constituir, por meio do espaço público, modos institucionais de conquistar espaço com suas ideias.

Isso reflete nas possibilidades de articulação entre uma proposta de reconhecimento das diversidades sexuais em ambiente escolar e a proposta de se desenvolver esse tema como parte do currículo transversalizado nas disciplinas escolares, impondo barreiras que, em muitos casos, tornam-se instransponíveis, não pela dificuldade de se fazer algo para mudar, mas porque essa mudança representa aberturas para que novas identidades possam se construir. Quanto a isso, não se pode esperar que novas identidades sozinhas realizem o processo de disputa por reconhecimento nas escolas. Existem possibilidades de aliar-se nessa disputa que podem servir de parâmetros para promover a cultura do respeito à diversidade sexual em ambiente escolar.

Essa possibilidade, como veem Graupe e Grossi (2013, p. 232), também pode ser movimentada pelos grupos de pesquisas ligados às universidades, principalmente se o combate à homo, lesbo e transfobia "for discutido com as/os professoras/es de todas as áreas do conhecimento e com a participação da comunidade escolar (pais e funcionários)". As escolas precisam pensar em maneiras de derreter práticas que solidificam modos normativos de ser, oferecendo mais possibilidades de vazão às maneiras mais inventivas e singulares.

É fundamental que a discussão sobre identidades de gênero e sexuais façam parte da rotina escolar, com um momento em que cada unidade escolar reflita profundamente sobre quem é esta travesti, este homossexual, esta lésbica, este bissexual, problematizando, com isso, quais são manifestações identitárias sob as quais se constituem pessoas que se diferem da norma. Nesse sentido, é importante que as escolas participem dos movimentos que são traçados pelos grupos de pesquisas das universidades.

\section{POLÊM!CA $\mid$ LABORE}


Torna-se necessário, ainda, assumir uma concepção de prática escolar que segregue menos e acolha mais. Acolher não no sentido de definir padrões e ensinar a dicotomia e polaridade entre os gêneros, mas uma prática de acolhida que transforme o ambiente escolar e as práticas pedagógicas, a partir das necessidades educativas que as estudantes trans trazem. Baseados nesta perspectiva, com este estudo, revela-se bastante oportuno oferecer novas formas de tratamento e qualificação do atendimento educacional às estudantes trans para que possam, no "lacre", que tanto integra seus discursos, alcançarem êxito nas escolas e seus itinerários formativos projetados para si.

O estudo explorou, ainda, na literatura sobre o tema, o universo da produção acadêmica que levanta possíveis situações que tornam mais problemático o reconhecimento de travestis nas escolas, mas não se esgotou com isso. Trouxe, também, exemplos do que pode ser feito para converter quadros de transfobias nas escolas, no entanto, é preciso o envolvimento da comunidade escolar nesse processo.

\section{Referências}

ANDRADE, L. N. de. Travestis na escola: assujeitamento e resistência à ordem normativa. 2012. 278f. Tese (Doutorado em Educação) - Universidade Federal do Ceará, Fortaleza, 2012. Disponível em: <http://bdtd.ibict.br/vufind/Record/UFSC_a16a99dd1f74573a45e28692dc0c8dac>. Acessado em: 19 de jan. de 2016.

BAUMAN, Z. Modernidade líquida. Trad. Plinio Dentzien. Rio de Janeiro: Jorge Zahar Editora, 2001.

BENEDETTI, M. R. Toda feita: o corpo e o gênero das travestis. Rio de Janeiro: Garamond, 2005

BENTO, B. Na escola se aprende que a diferença faz a diferença. Estudos Feministas. Florianópolis, mai./ago., p. 549-559, 2011.

BORTOLINI, A. (Coord.). Diversidade sexual na escola. Rio de Janeiro: Pró-Reitoria de Extensão/UFRJ, 2008.

BUTLER, J. Problemas de gênero: feminismo e subversão da identidade. 3. ed. Rio de Janeiro: Civilização Brasileira, 2010.

BRAGA, K. D. da S. Homofobia na escola: análise do livro de homofobia escolar. 2014. 200f. Dissertação (Mestrado em Educação) - Universidade Estadual Paulista “Júlio de Mesquita Filho", Presidente Prudente, 2014. Disponível em: << http://repositorio.unesp.br/bitstream/handle/11449/113831/000802257.pdf?sequence=1〉>. Acessado em: 23 de março de 2016.

BRASIL. Gênero e diversidade sexual na escola: reconhecer diferenças e superar preconceitos. Cadernos SECAD/MEC, 2007. Disponível em: 〈http://pronacampo.mec.gov.br/images/pdf/bib_cad4_gen_div_prec.pdf〉. Acessado em: 15 de Abril de 2014.

BRITZMAN, D. P. O que é esta coisa chamada amor? Identidade homossexual, educação e currículo. Revista Educação \& Realidade. V. 21, jan/jun, 1996.

\section{POLÊM!CA $\mid$ LABORE}


CRUZ, E. F. Banheiros, travestis, relações de gênero e diferenças no cotidiano escolar. Rev. psicol. polit. [online]. 2011, vol.11, n.21 p. 73-90. Disponível em:

<http://pepsic.bvsalud.org/scielo.php?script=sci_arttext\&pid=S1519-549X2011000100007\&lng=pt\&nrm=iso>. Acessado em: 12 de Fev. de 2016.

DELEUZE, G. Bergsonismo. Trad. Luis B. L. Orlandi. 34ª ed. São Paulo: 1999.

FOUCUALT, M. Ditos e Escritos IV: Estratégia, Poder-Saber. Trad. Manuel Barros da Motta. Rio de Janeiro: Forense Universitária, 2003.

História da sexualidade I: a vontade de saber. 6.ed. Rio de Janeiro: Graal, 1985.

Microfísica do Poder. Trad. Roberto Machado. 19. ed. Rio de Janeiro: Graal, 2004.

Vigiar e Punir. Trad. Raquel Ramalhete. 27. ed. Petrópolis: Vozes, 1987.

GRAUPE, M. E.; GROSSI, M. P. As ações do Núcleo de Identidades de Gênero e Subjetividades (NIGS) e a agenda política de combate à homofobia, lesbofobia e transfobia nas escolas. Revista Emblemass, v. 10, n. 2, p. 221-233, jul-dez, 2013. Disponivel em: 〈http://miriamgrossi.paginas.ufsc.br/files/2012/03/Visualizar27.pdf $>$. acessado em: 15 de jan. de 2016.

JUNQUEIRA, R. D. Homofobia nas escolas: um problema de todos. In: JUNQUEIRA, R. D. Diversidade sexual na educação: problematização sobre a homofobia nas escolas. Brasília: MEC/SECAD, 2009.

LOURO, G. L. Gênero, sexualidade e educação: uma perspectiva pós-estruturalista. Petrópolis, RJ: Vozes, 1997.

Um corpo estranho: ensaios sobre sexualidade e teoria queer. Belo Horizonte: Autêntica, 2008.

PENNA, F. de A. Sobre o ódio ao professor: entrevista com Fernando Penna. MOVIMENTO Revista de Educação, ano 2, n. 3. 294 - 301, 2015. Disponível em:

<http://www.revistamovimento.uff.br/index.php/revistamovimento/article/view/275/236>. Acessado em: $12 \mathrm{de}$ abril de 2016.

PERES, W. S. Cenas de exclusão anunciadas: travestis, transexuais, transgêneros e a escola brasileira. In: JUNQUEIRA, R. D. Diversidade sexual na educação: problematização sobre a homofobia nas escolas. Brasília: MEC/SECAD, 2009. p. 235-264.

PERES, W. S. Travestis, escolas e processos de subjetivação. Instrumento (Juiz de Fora), v. 12, p. 57-66, 2010.

SOARES, W. Vamos falar sobre ele: Como lidar com um aluno que se veste assim? Um reflexão sobre sexualidade e gênero. REVISTA NOVA ESCOLA Fev de 2015, ano 30, n. 279. Disponível em: << http://revistaescola.abril.com.br/formacao/educacao-sexual-precisamos-falar-romeo-834861.shtml >>. Acessado em: 15 de jan. de 2016.

SEFFNER, F. Equívocos e armadilhas na articulação entre diversidade sexual e políticas de inclusão escolar. In: JUNQUEIRA, R. D. Diversidade sexual na educação: problematização sobre a homofobia nas escolas. Brasília: MEC/SECAD, 2009. p. 125-140.

SWAIN, T. N. A invenção do corpo feminino ou “a hora e a vez do nomadismo identitário?”. Feminismos: teorias e perspectivas, v. 8, n. 112, 2000.

Recebido em: 14/07/2016.

Aceito em: 03/11/2016.

\section{POLÊM!CA $\mid$ LABORE}

Polêmica - Revista Eletrônica da Uerj - Rua São Francisco Xavier, 524, $1^{\circ}$ andar

bloco D, sl.1001 • Tels.: +55 21 2334-4088/4087 • http://www.e-publicacoes.uerj.br/index.php/polemica/index

http://www.labore.uerj.br • laboreuerj@yahoo.com.br 